\title{
Prenatal Programming of Renal Function: The Estimated Glomerular Filtration Rate is Influenced by Size at Birth in Apparently Healthy Children
}

\author{
ABEL LÓPEZ-BERMEJO, CARMEN SITJAR, ALICIA CABACAS, MONTSERRAT VÁZQUEZ-RUÍZ, \\ MARIA MAR GARCÍA-GONZÁLEZ, CARME MORA, PILAR SORIANO, MAR CALVO, AND LOURDES IBÁÑEZ
}

Department of Pediatric Endocrinology [A.L.-B.], Dr. Josep Trueta Hospital, Girona 17007, Spain; Departments of Pediatric Nephrology [C.S.], Pediatrics [A.C., M.V-R., M.M.G-G.], and Clinical Laboratory [C.M., P.S.], Hospital of Figueres, Figueres 17600, Spain; Department of Pediatrics [M.C.], Albera Salut, Peralada 17491, Spain; Endocrinology Unit [L.I.], University of Barcelona, Esplugues 08950, Barcelona, Spain

\begin{abstract}
Prenatal growth is known to affect glomerular function in adult life. It is unknown, however, whether this association is also present in children. In a cross-sectional study, we examined whether birth weight (BW) is associated with serum creatinine (measured by an improved Jaffe method) and GFR (estimated by the Haycock-Schwartz formula; eGFR) in 73 apparently healthy schoolage children ( 35 boys and 38 girls; age $9.5 \pm 0.4 \mathrm{yr}$ ). All children were born after singleton term pregnancies (gestational age $39.6 \pm$ $0.2 \mathrm{wk})$ with normal BW $(3.2 \pm 0.04 \mathrm{~kg})$. A significant decrease in serum creatinine and increase in the eGFR was evident by tertiles of BW-SD score (SDS) $(p=0.001$ and $p<0.0001)$. eGFR was correlated with BW-SDS $(r=0.45 ; p<0.0001)$, so that each unit increase in BW-SDS was associated with an increase in eGFR of 10 (95\% CI 5-14) $\mathrm{ml} / \mathrm{min}$ per $1.73 \mathrm{~m}^{2}$. In summary, estimates of glomerular function are in apparently healthy school-age children influenced by size at birth. These findings suggest early effects for the prenatal programming of renal function in humans. (Pediatr Res 64: 97-99, 2008)
\end{abstract}

S usceptibility to renal disease after low birth weight (LBW) is thought to be an additional dimension to the Barker hypothesis of prenatal programming of adult diseases $(1,2)$.

Spontaneous and induced LBW in rats results in reduced nephron number both at birth and in the adult life (3-5). Nephron number is also reduced in infants, children and adults with LBW (6-8).

Population-based studies show that LBW adults are at risk of developing chronic renal disease $(9,10)$. In a recent study, estimates of GFR (eGFR) were shown to be reduced in adults with LBW and to be directly associated with their BW (11). In young adults born very premature, LBW was also inversely associated with various parameters of glomerular function (12). GFR may be also influenced by prenatal growth restriction in neonates (13). To our knowledge, no association between BW and glomerular function has been reported in children.

We hypothesized that prenatal growth is related to renal function in childhood and studied the cross-sectional associ-

Received September 4, 2007; accepted February 1, 2008.

Correspondence: Abel López-Bermejo, M.D., Pediatric Endocrinology, Dr. Josep Trueta Hospital, Av. Francia s/n, 17007 Girona, Spain; e-mail: uden.alopez@ htrueta.scs.es

A. L.-B. is a Research Investigator of the Fund for Scientific Research "Ramon y Cajal" (Ministry of Education and Science, Madrid, Spain). L. I. is a Clinical Investigator of REDIMET, R676D (FIS, Instituto de Salud Carlos III, Madrid, Spain). ation between BW and GFR, as estimated by the HaycockSchwartz formula, in a sample of apparently healthy schoolage children. Our results suggest that size at birth is associated with glomerular function as early as in childhood. ${ }^{1}$

\section{METHODS}

In a hospital-based setting, 73 school-age Caucasian children ( 35 boys and 38 girls; age $9.5 \pm 0.4 \mathrm{yr}$ ) were selected for the study. Subjects were consecutively recruited among those seen at the outpatient pediatric clinics. All children included had normal variants of short stature, early-normal or delayed-normal puberty (14-16) but were otherwise healthy. They were all prepubertal or early pubertal (stage 2 ) at the time of the study, as based on the standards by Marshall and Tanner $(15,16)$.

Inclusion criteria were term birth after 37 to $42 \mathrm{wk}$ of a singleton gestation; BW appropriate [between +2 SD score (SDS) and -2 SDS for gestational age (GA)]. Exclusion criteria were gestational diabetes or hypertension; maternal use of alcohol, drugs, or illicit substances during gestation. In the proband, additional exclusion criteria were major congenital or chromosomal anomalies; abnormal blood counts, liver, kidney or thyroid functions or growth hormone deficiency, celiac disease, evidence of chronic illness, acute illness, or medication use within the previous month of inclusion.

The research was performed in accordance with the Declaration of Helsinki and was approved by the Institutional Review Board of Dr. Josep Trueta Hospital who waived the requirement for informed consent as the assessments taken were standard procedures in the evaluation of growth and puberty in the study subjects.

Age- and sex-adjusted SDS for current weight and height were calculated using regional normative data (17). BW and GA were obtained from standardized medical records. GA- and sex-adjusted SDS for BW were calculated using regional normative data (18).

Fasting venous blood was collected for screening of the various conditions listed above and for measurement of serum creatinine, which was accomplished using an improved Jaffe method on an automated ARCHITECT c800 instrument (Abbott Park, IL). The lower detection limit was $4.5 \mu \mathrm{M}$. The intra- and interassay coefficients of variation were less than $6 \%$ and no significant interference was found by common serum analytes. GFR was estimated by the Haycock-Schwartz formula, using serum creatinine (Screat in $\mu \mathrm{mol} / \mathrm{L}$ ) and height $(\mathrm{H}$ in $\mathrm{cm}$ ) as follows: $K \times \mathrm{H} / \mathrm{Screat}$, with a $K$ value of 46 for all ages (19). The estimation of glomerular function by this formula may be superior to that based on creatinine clearance in children (20). In our center, the eGFR was in good agreement (intraclass correlation coefficient $\rho=0.74, p=0.0007$ ) with that based on creatinine clearance in a sample of 15 children [aged 10.3 (95\% CI 8.7-12.0) yr] with normal renal function.

Statistical analyses were performed using SPSS version 12.0 (SPSS Inc, Chicago, IL). The relation between variables was analyzed by simple and partial correlation followed by multiple regression in a stepwise manner. Analysis of covariance using a general linear model and Bonferroni correction was used to seek differences in eGFR among groups defined by tertiles of BW-SDS. Significance level was set at $p<0.05$. The study had an $80 \%$

Abbreviations: BW, birth weight; eGFR, estimated glomerular filtration rate; GA, gestational age; LBW, low birth weight 
Table 1. Characteristics of the study subjects according to tertiles of birthweight SDS

\begin{tabular}{|c|c|c|c|c|c|}
\hline & \multirow[b]{2}{*}{ All subjects } & \multicolumn{3}{|c|}{ Birth weight SDS tertiles } & \multirow[b]{2}{*}{$p$} \\
\hline & & -2.0 to -0.7 & -0.7 to -0.1 & -0.1 to 1.6 & \\
\hline$N$ & 73 & 24 & 25 & 24 & \\
\hline Boys/girls $(n)$ & $35 / 38$ & $11 / 13$ & $13 / 12$ & $11 / 13$ & NS \\
\hline GA (wk) & 39.6 (39.2 to 39.9$)$ & $39.8(39.5$ to 40.1$)$ & $39.9(39.3$ to 40.4$)$ & 39.0 (38.3 to 39.7$)$ & 0.03 \\
\hline Birth weight (kg) & $3.2(3.1$ to 3.3$)$ & $2.9(2.8$ to 3.0$)$ & $3.2(3.1$ to 3.3$)$ & $3.5(3.3$ to 3.6$)$ & $<0.0001$ \\
\hline Birth weight SDS & $-0.3(-0.5$ to -0.2$)$ & $-1.2(-1.4$ to -1.0$)$ & $-0.4(-0.5$ to -0.3$)$ & $0.6(0.4$ to 0.8$)$ & $<0.0001$ \\
\hline Age $(\mathrm{yr})$ & $9.5(8.6$ to 10.3$)$ & $9.6(8.2$ to 11.0$)$ & 9.7 (8.0 to 11.5$)$ & 9.1 (7.5 to 10.7$)$ & NS \\
\hline Weight $(\mathrm{kg})$ & $31.9(28.4$ to 35.3$)$ & $31.1(25.7$ to 36.5$)$ & $31.0(25.8$ to 36.2$)$ & 33.7 (25.6 to 41.7$)$ & NS \\
\hline Height (cm) & $128(123$ to 133$)$ & $128(121$ to 135$)$ & $128(118$ to 138$)$ & $129(119$ to 138$)$ & NS \\
\hline BMI $\left(\mathrm{kg} / \mathrm{m}^{2}\right)$ & $18.4(17.5$ to 19.2$)$ & 18.1 (16.6 to 19.6$)$ & 18.1 (17.1 to 19.0$)$ & 18.9 (16.9 to 20.8$)$ & NS \\
\hline BMI SDS & $0.6(0.2$ to 1.0$)$ & $0.6(-0.2$ to 1.3$)$ & $0.5(-0.1$ to 1.0$)$ & $0.9(0.0$ to 1.8$)$ & NS \\
\hline Serum creatinine $(\mu \mathrm{mol} / \mathrm{L})$ & $56(53$ to 58$)$ & $59(55$ to 62$)$ & $54(50$ to 59$)$ & $52(47$ to 56$)$ & 0.005 \\
\hline eGFR $\left(\mathrm{mL} / \mathrm{min}\right.$ per $\left.1.73 \mathrm{~m}^{2}\right)$ & $110(106$ to 114$)$ & 102 (96 to 107$)$ & $109(103$ to 115$)$ & $120(112$ to 128$)$ & $<0.0001$ \\
\hline \multicolumn{6}{|c|}{ After adjusting for gender, GA, current age and BMI } \\
\hline Serum creatinine $(\mu \mathrm{mol} / \mathrm{L})$ & 56 (53 to 58$)$ & 59 (56 to 62$)$ & 54 (52 to 57$)$ & 51 (47 to 54$)$ & 0.001 \\
\hline eGFR $\left(\mathrm{mL} / \mathrm{min}\right.$ per $\left.1.73 \mathrm{~m}^{2}\right)$ & $110(106$ to 114$)$ & 101 (95 to 106$)$ & 108 (103 to 113$)$ & $121(115$ to 127$)$ & $<0.0001$ \\
\hline
\end{tabular}

Values are mean (95\% CI). SDS, standard deviation score; GA, gestational age; BMI, body mass index; eGFR, glomerular filtration rate, as estimated by the Haycock-Schwartz formula, using serum creatinine (screat in $\mu \mathrm{mol} / \mathrm{L}$ ) and height $(\mathrm{H}$ in $\mathrm{cm}$ ) as follows: $K \times \mathrm{H} / \mathrm{Screat}$, with a $K$ value of 46 for all ages. $p$ values are from linear trend ANOVA (nonadjusted data) and from general linear models (adjusted data).

power to detect a significant correlation between BW-SDS and eGFR with a Pearson correlation coefficient of at least 0.30 .

\section{RESULTS}

The clinical and laboratory characteristics of the study subjects are depicted in Table 1. To study the association between BW and both serum creatinine and the eGFR (Haycock-Schwartz formula), subjects were stratified by tertiles of BW-SDS (Table 1). A significant decrease in serum creatinine and increase in the eGFR was evident by tertiles of BW-SDS ( $p=0.001$ and $p<0.0001$, respectively, adjusted for gender, current age and BMI). Figure 1 depicts the association between BW-SDS and eGFR.

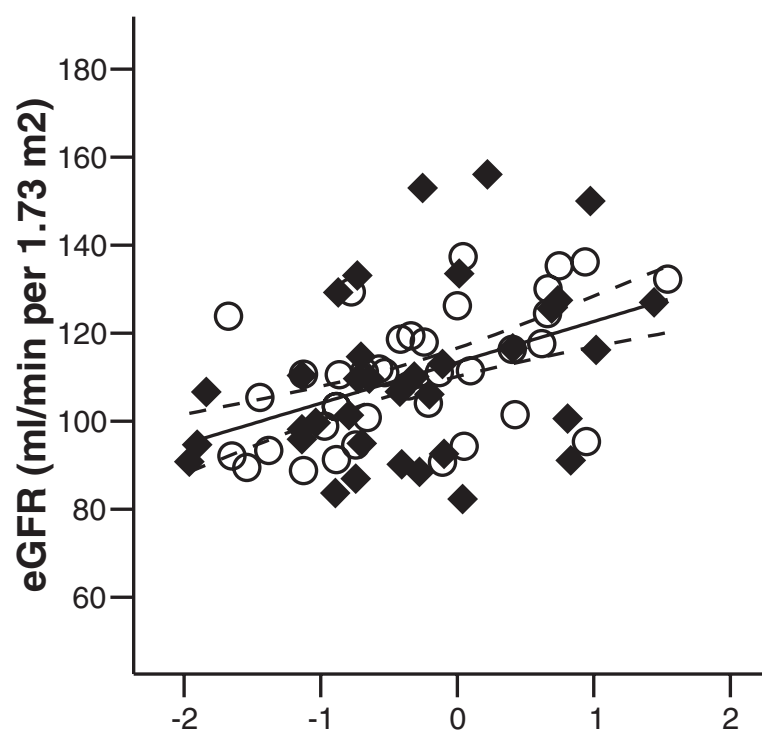

Birthweight SDS

Figure 1. Correlation graph of birth weight SDS with the estimated GFR (eGFR; Haycock-Schwartz formula). A regression line with 95\% CI of mean values is shown for the study population of boys (closed diamonds) and girls (open dots) studied as single group. Pearson's correlation analysis: $r=0.45$, $p<0.0001$.
In these children, serum creatinine was strongly correlated with age and current height (both $r=0.66 ; p<0.0001$ ), as expected, and was correlated with BW-SDS before and after accounting for age and current height in a partial correlation analysis $(r=-0.32 ; p=0.006$ and $r=-0.41 ; p<0.0005$, respectively). The eGFR was also correlated with BW-SDS $(r=0.45 ; p<0.0001)$, so that each unit increase in BW-SDS was associated with an increase in eGFR of 10 (95\% CI 5-14) $\mathrm{ml} / \mathrm{min}$ per $1.73 \mathrm{~m}^{2}$.

In a multiple regression analysis with eGFR as the dependent variable both BW-SDS $(\beta=0.45, p<0.0001)$ and age $(\beta=0.26, p=0.01)$ were significantly associated with eGFR, explaining, respectively, $19 \%$ and $6 \%$ of its variance. These associations were gender independent.

\section{DISCUSSION}

To our knowledge, this is the first report to show a association between BW and GFR, as inferred by the HaycockSchwartz formula, in apparently healthy, normal BW, at term children.

In autopsy kidneys, a direct correlation has been reported between $\mathrm{BW}$ and the number of glomeruli and this association was linear over a large range of $\mathrm{BW}$, so that an increase of 257,426 glomeruli was evident per kilogram increase in BW (8). It is noteworthy that the strongest association between theses parameters was observed in infants, followed by children and by adults $(7,8)$, which indicates that other factors account for the variance of glomeruli number in older children and adults. Renal volume, which is a likely proxy for nephron number, is also decreased in fetuses with intrauterine growth restriction (21). In toddlers and in children and adolescents, ultrasonographically assessed kidney volume was directly related to BW $(22,23)$. These observations agree with the current concept that prenatal growth restriction can adversely influence the nephron number in both children and adults (24).

Despite a wealth of data indicating that in adults various parameters of renal function are related to BW (9-11), and 
despite the fact that a low nephron number in children may be a risk factor for essential hypertension and cardiovascular disease (25), to our knowledge, no clinical association between BW and renal function has been previously sought in healthy children. Our findings suggest for the first time that prenatal growth, besides its morphologic effect on nephron number, has functional consequences in the kidney as early as in childhood.

In summary, estimates of glomerular function are in apparently healthy school-age children influenced by size at birth. These findings suggest early effects for the perinatal programming of renal function in humans and may have clinical implications in the prevention of end-organ damage in the population at risk for renal disease.

\section{REFERENCES}

1. Barker DJ, Osmond C, Golding J, Kuh D, Wadsworth ME 1989 Growth in utero, blood pressure in childhood and adult life, and mortality from cardiovascular disease. BMJ 298:564-567

2. Hoy WE, Rees M, Kile E, Mathews JD, Wang Z 1999 A new dimension to the Barker hypothesis: low birthweight and susceptibility to renal disease. Kidney Int 56:1072-1077

3. Merlet-Benichou C, Gilbert T, Muffat-Joly M, Lelievre-Pegorier M, Leroy B 1994 Intrauterine growth retardation leads to a permanent nephron deficit in the rat. Pediatr Nephrol 8:175-180

4. Langley-Evans SC, Welham SJ, Jackson AA 1999 Fetal exposure to a maternal low protein diet impairs nephrogenesis and promotes hypertension in the rat. Life Sci 64:965-974

5. Schreuder MF, Nyengaard JR, Fodor M, van Wijk JA, Delemarre-van de Waal HA 2005 Glomerular number and function are influenced by spontaneous and induced low birth weight in rats. J Am Soc Nephrol 16:2913-2919

6. Hinchliffe SA, Lynch MR, Sargent PH, Howard CV, Van Velzen D 1992 The effect of intrauterine growth retardation on the development of renal nephrons. Br J Obstet Gynaecol 99:296-301

7. Manalich R, Reyes L, Herrera M, Melendi C, Fundora I 2000 Relationship between weight at birth and the number and size of renal glomeruli in humans: a histomorphometric study. Kidney Int 58:770-773

8. Hughson M, Farris AB III, Douglas-Denton R, Hoy WE, Bertram JF 2003 Glomerular number and size in autopsy kidneys: the relationship to birth weight. Kidney Int 63:2113-2122
9. Lackland DT, Bendall HE, Osmond C, Egan BM, Barker DJ 2000 Low birth weights contribute to high rates of early-onset chronic renal failure in the Southeastern United States. Arch Intern Med 160:1472-1476

10. Tulassay T, Vasarhelyi B 2002 Birth weight and renal function. Curr Opin Nephrol Hypertens 11:347-352

11. Gielen M, Pinto-Sietsma SJ, Zeegers MP, Loos RJ, Fagard R, de Leeuw PW, Beunen G, Derom C, Vlietinck R 2005 Birth weight and creatinine clearance in young adult twins: influence of genetic, prenatal, and maternal factors. J Am Soc Nephrol $16: 2471-2476$

12. Keijzer-Veen MG, Schrevel M, Finken MJ, Dekker FW, Nauta J, Hille ET, Frolich M, van der Heijden BJ; Dutch POPS-19 Collaborative Study Group 2005 Microalbuminuria and lower glomerular filtration rate at young adult age in subjects born very premature and after intrauterine growth retardation. J Am Soc Nephrol 16:27622768

13. Frattarelli DA, Ergun H, Lulic-Botica M, Lehr VT, Aranda JV 2005 Vancomycin elimination in human infants with intrauterine growth retardation. Pediatr Infect Dis J 24:979-983

14. Wit JM 2007 Idiopathic short stature: reflections on its definition and spontaneous growth. Horm Res 67:50-57

15. Marshall WA, Tanner JM 1969 Variations in pattern of pubertal changes in girls Arch Dis Child 44:291-303

16. Marshall WA, Tanner JM 1970 Variations in the pattern of pubertal changes in boys. Arch Dis Child 45:13-23

17. de la Puente ML, Canela J, Alvarez J, Salleras L, Vicens-Calvet E 1997 Crosssectional study of the child and adolescent population of Catalonia. Ann Hum Biol 24:435-452

18. Vicedo EM, Mataró D, Martínez S, Gavaldá L, Sabriá J 1998 [Neonatal weight charts for the population served by Dr Josep Trueta University Hospital at Girona]. Prog Obstet Ginecol (Bucur) 41:215-220

19. Haenggi MH, Pelet J, Guignard JP 1999 [Estimation of glomerular filtration rate by the formula GFR $=\mathrm{K} \times \mathrm{T} / \mathrm{Pc}]$. Arch Pediatr 6:165-172

20. Martini S, Prevot A, Mosig D, Werner D, van Melle G, Guignard JP 2003 Glomerular filtration rate: measure creatinine and height rather than cystatin $\mathrm{C}$ ! Acta Paediatr 92:1052-1057

21. Silver LE, Decamps PJ, Korst LM, Platt LD, Castro LC 2003 Intrauterine growth restriction is accompanied by decreased renal volume in the human fetus. Am J Obstet Gynecol 188:1320-1325

22. Spencer J, Wang Z, Hoy W 2001 Low birth weight and reduced renal volume in Aboriginal children. Am J Kidney Dis 37:915-920

23. Schmidt IM, Chellakooty M, Boisen KA, Damgaard IN, Mau Kai C, Olgaard K, Main KM 2005 Impaired kidney growth in low-birth-weight children: distinct effects of maturity and weight for gestational age. Kidney Int 68:731-740

24. Haycock GB 1998 Development of glomerular filtration and tubular sodium reabsorption in the human fetus and newborn. Br J Urol 81:33-38

25. Amann K, Plank C, Dotsch J 2004 Low nephron number-a new cardiovascular risk factor in children? Pediatr Nephrol 19:1319-1323 